\title{
A Study on the Blended-Teaching Mode Combining MOOCs and Flipping Classroom in College English Teaching
}

\author{
Guangcai Li \\ Jilin Agricultural University, Changchun, China \\ Email:372415102@qq.com
}

Keywords: MOOCs; Flipping classroom; Micro lecture; Blended teaching mode

\begin{abstract}
This paper aims to introduce the concept and connotation of MOOCs and flipping classroom, analyze the necessity and feasibility of the combination of MOOCs and flipping classroom, and point out the practical strategies of the combination of MOOCs and flipping classroom from three aspects: front-end analysis, activities and resources design and multiple evaluation system. It is pointed out that the B-Teaching mode already has a certain theoretical support, the resources and environmental conditions, which can meet the students' individual learning needs, improve the professional quality of the teachers, and realize the goal of improving the curriculum structure of the college English and enhance the teaching effectiveness.
\end{abstract}

\section{Introduction}

With the rapid development of teaching information, a large number of large-scale online open courses are emerging gradually like spring mushroom. The Blended Teaching mode (B-teaching mode) combining online and offline teaching materials has been discussed, focused on and practiced in college English classes, among which the combination of MOOCs and flipping classroom is one of the representatives. According to many years of teaching practice experience based on the B-teaching mode, the author is expected to discuss the necessity and feasibility of applying this model to our college classes and the resultant problems and specific solutions during the course of application and practice.

The traditional teaching mode of the university is based on "teaching", while the B-teaching mode, a new teaching mode with the characteristics of digitalization, informatization and network, will definitely have great influence on the traditional teaching mode with the value orientation of "learning". Huang Zhen, former vice-president of Shanghai Jiaotong University, maintains that the online curriculum model will lead to "learning revolution", and that a visible change will be the appearance of flipping classroom, which promises the shift from the teacher-centered model to as the student-centered model.

At present, colleges and universities across the country are vigorously promoting the reforms of educational and teaching modes with the fundamental purpose to improve the quality of talents training, of which the most important thing is to start from the quality of classroom teaching. Currently, there is no denying that many factors still influence the teaching quality. For example, the big classes with fifty or sixty students are very commonplace in colleges and universities; with the further reform, classroom periods are limited to some extent. As a matter of fact, the chances for the students to be exposed to targeted language are less than before. Therefore, the reformed teaching mode needs the MOOCs or something like that as a platform to provide more opportunities for students to acquire the targeted language. In order to further teaching reform, it is required that the scale of the class should be reduced to the number of approximately 30 so that the teachers can effectively guide every student under the concept of the B-teaching mode. On the basis of the mode, inquiry learning mode should be encouraged as a part of teaching reform. In addition, the teachers should be allowed to adopt interactive teaching mode. In class the teachers are expected to teach their students with heuristic teaching approaches, touch different issues with their students with critical thinking, and examine their students with non-standard answers to the questions from the 
paper. To a great extent, the reformed teaching model guides students to take the initiative to learn and make active exploration. In addition, MOOCs platform will make up for the deficiency in the construction of foreign language teaching materials allowing students to have access to the new language resources, to extend their horizon, and to raise their interests in English.

To put it briefly, the widespread application of MOOCs into traditional class will demonstrate the "student-oriented" teaching philosophy to the maximum. Based on the sophisticated design of "micro-lecture" and centering on the "flipping classroom", B-teaching model is doomed to improve their learning performance. The MOOCs can effectively solve a series of problems such as the backwardness of teaching contents and approaches, alleviation of the plight of high-level teachers, students' weak awareness of innovation, and deficiency of learning ability. In a way the adaptation of MOOCs can also effectively reduce the outflow of high quality students in China.

\section{Literature Review}

Based on large data and cloud computing technology the B-teaching mode, a new type of teaching mode characteristic of informationization, integrates high quality teaching resources and closely aims at the teaching objectives, ultimately develop students' language competence comprehensively with the improvement of learning efficiency and the consolidation of the students' language knowledge and skills [1]. The mode depends greatly on the online resources-MOOCs and offline resources-teacher-directed flipping classroom, which are essential for the teachers to carry out different teaching tasks with the aid of modern technology.

MOOCs. MOOCs refer to Massive Open Online Course, large-scale open network courses. Among them, Massive refers to the number of registered users; Open refers to no threshold to a high degree; Online refers to anytime online; Courses refer to the curriculum, an independent and complete teaching system which includes experience, feedback, collaborative interaction and assessment evaluation. In short, MOOCs are open courses based on the network platform, which extend the scope of the traditional teaching mode.

At the beginning of the education reform, the Massive Open Online Courses (MOOCs) has increased in recent years, which is greatly different from previous approaches to online education. MOOCs represent the latest stage in the evolution of open educational resources for students around the globe. They are considered to be a recent innovation in online learning with virtual technology-enhanced learning environments. The network technology facilitates scalable peer-based learning and the dominant channel through which teachers and students can communicate. Their advantages are large scale, openness and self-organization. MOOCs are developed to enhance the effectiveness of teaching and learning. On the one hand, MOOCs offer teachers the opportunity to reach a large number of students worldwide. On the other hand, MOOCs enable students to have access to online resources freely and conveniently. The education should be open, provided by the most reputable universities, which attract substantially larger number of students than traditional classroom education. Furthermore, MOOCs are communities of people that share common interests. Recent research shows that MOOCs are becoming widely-discussed new topics in education. Open is the most important feature of a MOOC. There are at least five attributes of openness that are essential components of MOOCs: free access, adaptation, remixing, sharing and collaboration [2]. Furthermore, massiveness represents a second level of importance. Online indicates that all the learning experience is realized through the Internet. Thus, the course generates different experiences through free-access, self-learning video tutorials online.

MOOCs don't have only a clear pedagogical purpose but also have constituent components and most MOOCs consist of relatively short video lectures, related content, and feedback, which are managed either through peer-review and group collaboration or by automation. Micro-lecture is the most frequent and extensive use of fragmented teaching resources in MOOCs.

Flipping Classroom. The concept of 'flipping the classroom' has received considerable interest in recent years [3]. The term 'flipping the classroom' refers to having recorded lectures available to 
students online and using class time for the instructor to work out extra examples and facilitate more interaction in problem solving. The term 'flipping' refers to the idea of having students reverse the normal class routine of students sitting in class listening to a lecture and leaving to do homework on their own. In a flipped classroom, students listen to the lecture or other instruction on their own, often via some form of access to the internet, and class-time is used for discussion, independent work with teacher guidance, group work, peer instruction, teacher led examples, etc.

The flipping classroom is an innovative teaching model that improves the teacher - student relationship in the traditional classroom teaching model by changing the process of knowledge transfer and knowledge internalization, and plans the allocation and use of classroom time. The flip classroom consists of two modules - curriculum design and classroom activities [4]. In the course design, the teacher pre-records the video according to the teaching goal and develops the teaching strategy and the teaching contents, the students' self-access teaching resources; in the classroom activity, the teacher changes from the traditional leader to the facilitator and the instructor who guides or directs the students personally.

As a new teaching model, flipping classroom changed and will change the teaching process as well as the role of teachers and students. Flipping classroom thoroughly subvert the traditional teaching methods of "teacher-based and students-assisted", requiring teachers to update the teaching concept, but also requires them to have a certain degree of information technology capabilities, such as the design and edition of micro-lectures and videos.

Flipping classroom and MOOCs are closely interrelated. MOOCs are the carrier of the classroom while flipping classroom is an essential part of MOOCs, hence they are complementary in terms of advantages. MOOCs can be intensive and efficient delivery of knowledge, at the same time flipping classroom is conducive to solve the problems and issues the students encountered in the personalized learning process.

\section{The Necessity and Feasibility of B-teaching Mode}

In college, it is ideal for the students to have the opportunities to choose their own learning resources according to their own interests. Meanwhile, Colleges and universities should offer sufficient resources at their students' disposal, therefore they are better to entitle their students to free online resources in order to facilitate their teaching process and contents, which is their primary mission to educate and cultivate their students. Therefore, college English teaching needs to enrich the curriculum resources to meet the diversified learning needs of learners.

There is no doubt that MOOCS - online modularized learning resources characteristic of "open, themed", will be provided to the students will encourage and stimulate students to make their own choices on demand according to their will and interest. Flipping classroom will be efficiently and effectively complementary for learners to study. Most important of all, the blended teaching mode will facilitate learners to allocate their own learning time and fully meet the needs of diversification. The B-teaching mode can greatly improve the teacher-student relationship of the traditional domination and dependence, and awaken the students' initiative and autonomy. Through the collaborative teaching of MOOCs and flipping classroom teaching, chances are that the structure of college English teaching curriculum promises to leap for a long stage and finally improve teaching effect.

In recent years, China has implemented a variety of teaching means with multimedia and multimodal English teaching, especially with the emergence of MOOCS in different fields, online learning and classroom teaching has gradually been blended, therefore it followed that college English blended teaching environment had a certain basis and had been created to some extent. Many research results also confirmed that the blended teaching and learning is doomed to enhance the effectiveness of college English leaching. It will not only play the teachers' leading role, guiding and inspiring their students in the teaching process, but also can lay emphasis on the learner's subject position and improve the learning initiative and creativity of the learners. MOOCs 
are equipped with adequate online educational resources and a good curriculum structure, a unique theme knowledge-presenting style and perfect micro-curriculum modules. In order to complement the deficiency of MOOCS in the classroom management and teaching evaluation, it is crucial for teachers to introduce the flipping classroom to monitor and evaluate the teaching and learning effect. If the blended classroom goes normal just as the traditional classroom, undoubtedly, the teaching environment will form a harmonious ecosystem. In this case flipping classroom will be a comprehensive system of evaluation and assessment, showing a high degree of integration of online and offline resources. With the popularity of the Internet, flipping classroom teaching and MOOCs are widely used in college English teaching activities; it is not a long way to form a certain resource environment and teaching foundation.

The training and growth of teachers are one of the core factors to improve the teaching effect of college English and related courses. On the basis of original teaching notion and knowledge structure, B-teaching mode has brought about some changes even reforms in many perspectives such as the teaching objectives, teaching thinking, teaching methods, and teaching resources and at the same time proposes new challenges. With the strong urge or desire to be qualified teachers in the teaching community, they have to enrich the relevant professional knowledge and technical skills through the involvement of the design of the MOOCs to achieve their basic professional level. With the implementation of the B-teaching mode, it is compulsory that English teachers should learn about and even make best use of English teaching techniques, use and master a variety of new application software and resource platforms to improve their overall quality and information ability. The B-teaching mode can play a vital role in training teachers to a large extent, which can effectively solve the problem of increasing demand for college English teachers. In view of the big classes in colleges and universities, the teachers are required to fulfill their teaching duty with carefulness and definite directions.

\section{Application of the B-Teaching Mode in College English Teaching}

No doubt, there are various teaching approaches with the rapid development of teaching techniques and easy access to a range of online resources in teaching community. The learned teachers or instructors have brought out many a teaching method or means. The B-teaching mode has become one of the most impressive teaching modes. The performance of students in blended and traditional versions of a course is compared within the context of students' prior academic achievement. The blended version of the course used flipped and flexible instructional modes, in which only online lectures were available, class periods were used for complementary learning activities, and there was no punitive attendance policy.

Therefore, the overall design of teaching process shows its significance resulting from the fragmentation of knowledge. The best result for teaching design is the perfect combination between online resources and offline teaching guided and evaluated by the teachers and students' peers. The requirements for rational and systematic design come naturally. The teaching design of the B-teaching mode can be generally divided into three stages: Before-class analysis, design of activities and resources, design of teaching multi-evaluation [3].

Pre-class Analysis. The pre-class analysis includes the teaching notion, the design of teaching structure and the analysis on the current situations of relevant educational resources employment, as well as the teaching objects, the teaching goal, the teaching contents and the evaluation assessment system. The whole series of teaching aspects have to be taken into thorough consideration. Take teaching objects as an example, in a teacher's mind, motivated students are usually those who participate actively in class, express interest in the subject-matter, and study a great deal. Teachers can easily recognize characteristics such as these. They also have more opportunity to influence these characteristics than students' reasons for studying the second language or their attitudes toward the language and its speakers. If we can make our classrooms places where students enjoy coming because the content is interesting and relevant to their age and level of ability, where the 
learning or teaching goal are challenging yet manageable and clear, and where the atmosphere is supportive and non-threatening, we can make a positive contribution to students' motivation to learn. As a result, the teachers or instructors and authorities concerned have to make a thorough and thoughtful contemplation about the coming class. When faced with a large range of MOOCs resources, it seem more significant to combine the online resources and offline guidance. In view of these conditions, the design, such as teaching objectives, teaching contents, teaching structure and evaluation methods, have be based on the actual situation of students which serves as the premise.

Students are the main participants of English teaching and learning activities, the subjects of teaching practice and the embodiments of teaching effectiveness. Only by thoroughly analyzing the students' English proficiency, personality traits and learning styles, can teachers effectively improve the basic students' ability to use English, especially listening and speaking ability and writing ability, based on the design and implementation of the B-teaching mode. At the same time, under the guidance of the concept of quality education, teachers should develop students' comprehensive cultural literacy and communicative competence and cultivate learners' enthusiasm and autonomy in learning, so that students can master effective learning methods and learning strategies to lay solid foundation for future development of second language acquisition.

Design of Targeted Activities and Resources. According to the before-class analysis on teaching objectives, the teachers determine the teaching plan, unit contents and resource types, which can be systematically integrated into an effective and efficient teaching mechanic. The design can be targeted for different students in different classes to assign different learning tasks, such as learning micro-lecture videos in MOOCs, complete the unit test or assessment and so on. Definitely it is a necessary move to develop different evaluation criteria.

The B-teaching mode will cross the boundary of every period regulated by the teaching plan from the authority so that teachers are the full-time worker, which means they should offer their teaching services without time limitations whether online or offline. In terms of Online counseling, it mainly includes online counseling and group exchanges. In order to facilitate the whole teaching process online or offline, teachers should establish a course exchange through the WeChat or QQgroup to make interactive discussion between teachers and students, students and students. Previous to the discussion, teachers allow their students to be exposed to the MOOCs and relevant online materials acting on their teaching plan. In the process of online learning, learners raise their problems encountered and their teachers answer or discuss them through the exchange group. It is noted that the teachers are required to give immediate responses to the diverse questions; otherwise the students will lose their enthusiasm to online learning. MOOCs, as an online teaching resource, are widely used in online teaching pre-class activities, and have to be selected with definite directions or targets so as to serve as the complementary role. Directed at a single topic or some key difficult problems, the teachers can make detailed analysis and interpretation through micro-videos.

With regard to offline flipping classroom, the teachers should fulfill their duty severely and strictly. That is to say, classroom activities have to play a vital role in enhancing teaching effects by carrying out different tasks such as discussion, questioning and answering, student display and other interactive forms. Personally, the students will be able to complete self-judgment about the relevant self-learning process. The teacher can guide or direct their students to solve the problems and confusion; finally, the layout of the next session will be displayed before the students, to remind the next face-to-face focus and class time [5]. As a consequence, the flipping classroom is one of the important means of B-teaching mode, and it can increase the interaction and contact time between students and teachers in various links.

Design of Multi-evaluation System. Teaching assessment is divided into the usual formative assessment and the final assessment [6]. Formative assessment consists of two parts: online participation in MOOCs and offline participation in flipping classroom. The online part mainly includes learning record, classroom attendance and performance, homework and test scores, community and group participation etc. offline face-to-face flipping classroom includes classroom attendance and performance, unit operation and test, interactive discussion, teachers' and peers' 
assessment and other activities. Final examinations include course completion certificates or online graduation tests and school-based curriculum examinations. Two assessments are supposed to be done in accordance with the evaluation criteria, each of which accounts for a certain proportion. The evaluation system combining the two assessments not only includes the evaluation of the learners' learning effect, but also the evaluation of the teachers' teaching effect, among which learning effect should be the focus. Its focuses should be on improving or promoting the content of teaching reform, such as the merits and demerits of online teaching resources, that is the choice of MOOCs, the rationalization of teaching activities, the appropriateness of the teaching information means, and the improvement in learner's learning initiative, and the learner's individual differences in teaching and learning effects. Ultimately it is decided whether the B-teaching mode can promote the all-round development of learners' comprehensive abilities.

\section{Conclusion}

As a matter of fact, from my observation of the B-teaching mode, majority of the students responded that it increased their interest in English, encouraged them in developing independent learning skills. They experienced better understanding of the units assigned by the teacher, and higher level of interaction with the teacher during face-to-face sessions. Most of the faculty members agreed that blended learning motivated students to do self-study, helped them in developing higher cognitive skills and enhances learning.

Very clear teaching goals should be determined before embarking on any change in teaching mode and this is no exception. If we set aside the problems from MOOCs, large classes in flipping classroom require careful organization to avoid the classroom falling into chaos and confusion so preparations for the transition are imperative. This was a worthwhile effort and students benefited from this first effort in MOOCs, but it did require considerable time to implement in an organized manner. Students in the early stages of their college experience often suffer from a lack of self-discipline so some effort to force them to keep up with the recorded lectures is useful. There is no denying that incorporating interesting video demonstrations added to the interest of the recordings. Most computer microphones are not adequate and it would be very frustrating to listen to a poorly recorded lecture. For a subject like English, simple instructor led problem-solving for long periods of time can be tedious. I find peer-instruction to be beneficial where students work out problems individually and then the students who had the correct answer teach the others how to do the problem.

The current B-teaching is currently starting from scratch, facing many problems such as learning concepts, learning habits and other issues, and a certain amount of time practice. The individual differences and autonomy of teachers and students are the key factors that affect the teaching effect. Therefore, it is necessary to combine the community interaction and the face-to-face interactive cooperation of the classroom to reposition the college English teaching system under the B-teaching mode, and gradually improve the autonomy of the individual in the whole system, and provide the learners with abundant education resources for college English teaching to find a better space for development.

\section{References}

[1] Bergmann, J. Waddell, To flip or not to flip? Learning and Leading with Technology. (2012)

[2] Berrett, D. How flipping the classroom can improve the traditional lecture. Chronicle of Higher Education. (2012)

[3] Chen J. MOOCs construction and implementation strategy. Beijing TV Broadcast Journal. 2014 (1): $33-42$.

[4] Chen Y. K., Tian A.L. The Introduction of MOOCs and Flipping Classroom. Shanghai: East China Normal University Press, (2014) 
[5] Gu X.F. MOOCs in the Use and Prospects in College English Teaching [J]. English teachers (2015)

[6] Shapiro, M. Flipped classroom turns traditional teaching upside down. Suburban Journals. (2013) 